\title{
Rare but not so rare: The evolving spectrum of Whipple's disease
}

\author{
John M Conly MD FRCPC ${ }^{1}$, B Lynn Johnston MD FRCPC ${ }^{2}$
}

$\mathrm{K}_{1}^{\mathrm{n}}$ nowledge about Whipple's disease began to emerge in 1907, when George Hoyt Whipple recognized the first case of the disease that now bears his name. He reported the case of a 36-year-old physician with "a gradual loss of weight and strength, stools consisting chiefly of neutral fat and fatty acids, indefinite abdominal signs, and a peculiar multiple arthritis" (1). Findings at autopsy consisted of polyserositis, aortic valve vegetations and deposition of fat in the intestinal mucosa and regional lymph nodes with marked infiltration by foamy macrophages (1). It was originally thought to be a disorder of fat metabolism, and the term 'intestinal lipodystrophy' was proposed. Whipple's disease has since been recognized as a rare, multivisceral, chronic disease with a clinical presentation dominated by a symptom triad of diarrhea, weight loss and malabsorption. However, digestive symptoms are often preceded for months or years by other symptoms, the most common being arthralgia, although cardiovascular, neurological or pulmonary involvement may be more prominent at times. Once considered the ideal case report, recent characterization of Tropheryma whippelii by means of broad range bacterial ribosomal DNA polymerase chain reaction (PCR) analysis $(2,3)$ and its subsequent cultivation (4) has led to a veritable explosion of individual case reports, case series and hitherto unrecognized manifestations of the disease, such that it is now considered an underdiagnosed infectious disease (5). It is timely to provide an update on new developments in Whipple's disease.
The Whipple's bacterium, T whippelii, has been identified and characterized at the molecular level, and a recent serological test has been proposed following its successful cultivation (5). $T$ whippelii is a Gram-positive bacillus having a uniform bacillary shape, and surrounded by a unique and thick cell wall. Electron microscopy reveals that the Whipple's organism contains a trilaminar plasma membrane surrounded by a homogeneous cell wall in turn surrounded by a trilaminar membrane structure. The central location of the tubules and vesicles is typical of other Grampositive species. Phylogenetic analysis using $16 \mathrm{~S}$ ribosomal DNA sequence amplification with universal primers has revealed that the bacterium is a member of the Actinomycetes family $(2,3)$. Further analysis has placed the organism between Cellulomonas species and the group of actinomycetes with group B peptidoglycan in terms of its phylogeny (6). It is also related to Corynebacterium aquaticus and Rhodococcus species, and weakly related to Streptomyces species and mycobacteria (6). The organism has been difficult to cultivate, and its propagation in human macrophages pretreated with interleukin (IL)-4, as previously reported in 1997, has not been reproduced (7). Raoult et al (4) recently reported the propagation of the organism, coming from an infected heart valve, in a human fibroblast cell line and observed a cytopathic effect after 65 days of incubation. Organisms were observed using several staining techniques. After multiple passages, an infected cell monolayer was produced with an estimated doubling

\footnotetext{
${ }^{1}$ University Health Network, University of Toronto, Toronto, Ontario; ${ }^{2}$ Queen Elizabeth II Health Sciences Centre and Dalhousie University, Halifax, Nova Scotia

Correspondence: Dr John Conly, Department of Medicine, Division of Infectious Diseases, Suite 13-118 Norman Urquhart Wing, Toronto General Hospital, University Health Network, 200 Elizabeth Street, Toronto, Ontario M5G 2C4. Telephone 416-340-4858, fax 416-340-5047, e-mail john.conly@uhn.on.ca and Dr Lynn Johnston, Room 5014 ACC, Queen Elizabeth II Health Sciences Centre, 1278 Tower Road, Halifax, Nova Scotia B3H 2Y9. Telephone 902-473-8477, fax 902-473-7394, e-mail ljohnsto@is.dal.ca
} 
time of 18 days under the conditions described. Using cultured material as the antigen, these authors (4) developed a serological test and found elevated titres of immunoglobulin $M$ antibody in seven of nine patients with clinical Whipple's disease but in only three of 40 controls.

The incidence rate of Whipple's disease is low. There is no accurate estimate of either the prevalence or death rate because of this low incidence rate. Dobbins (8) analyzed 676 patients and found fewer than 18 cases/year in the 1960s and 30/year in the 1980s; however, the population also doubled between these time periods. Deaths from Whipple's disease are usually a result of failure to diagnose the disease, lack of antibiotic treatment, or delayed initiation of treatment with central nervous system (CNS) or cardiac complications. Of the 676 patients analyzed, $97 \%$ were white and two-thirds were farmers, construction workers or machinists (8). The reported age range varies widely (one to 81 years), but the disease appears to affect primarily middle-aged to elderly males. The well known male predominance remains unexplained. A genetic susceptibility has been suggested by the observations that about $30 \%$ of patients are human leukocyte antigen-B27postive and by the chronic relapsing nature of the illness. The notion of coexistent host impairment is supported by the reports of opportunistic infections in some patients with Whipple's disease (9). Studies have found a reduced CD4 to CD8 $\mathrm{T}$ cell ratio in circulating and lamina propria $\mathrm{T}$ cell populations, a shift toward mature $\mathrm{T}$ cell populations and increased $\mathrm{T}$ cell proliferative responses $(10,11)$. In addition, impaired $\mathrm{T}$ cell proliferative responses have been noted, and there appears to be a downregulated $\mathrm{T}$ cell-mediated response $(12,13)$. These defects are found not only in those with acute disease but also in those in remission. Difficulty in phagocytosis or degradation of the intracellular Gram-positive bacteria has been described as well $(8,14)$. The hypothesis of a possible cell-mediated macrophage activation defect is supported by experiments (15) in which phagocytes deactivated with IL-4 (also IL-10 and dexamethasone) were rendered to be permissive to intracellular $T$ whippelii propagation. This Th2-like cytokine profile suggests that host factors, such as Th1 and Th2 imbalance, may play a role in disease pathogenesis.

Although the source of acquisition is unknown, many observations suggest an environmental origin for $T$ whippelii. Related organisms have known environmental habitats. The epidemiological observation of a high frequency of farmers and carpenters among those with Whipple's disease is also supportive (8). The organism has been identified recently in specimens from sewage treatment plants (16). Two recent reports suggest a wider distribution of $T$ whippelii in the general population $(17,18) ; 35 \%$ (14 of 40 ) of saliva samples of healthy subjects were positive for $T$ whippelii, and $13 \%$ (14 of 105) of intestinal biopsy or gastric juice specimens from patients undergoing endoscopy were positive for the organism using PCR analysis.

The bacterium most commonly invades the intestinal lamina propria and the vacuoles of 'foamy' macrophages. It may also be found in other intestinal mucosal structures such as polymorphonuclear cells, smooth muscle, capillaries, lymphocytes, plasma cells and mast cells. The route of invasion is via the lamina propria and basal intercellular spaces rather than the intestinal lumen. The low virulence Whipple's bacteria are able to invade with little provocation of the host immune system. Noncaseating granulomas, a localized inflammatory response to persistent antigen, are found in less than $10 \%$ of patients. Infiltration of the lamina propria with large macrophages containing periodic acid-Schiff (PAS)-positive inclusions is a cross-reaction with bacterial glycoproteins located in the cell wall. The duodenum and jejunum are the sites most frequently affected, with disruption of the villous architecture. This presumably is the cause of the steatorrhea and malabsorption syndrome that are the hallmarks of classic Whipple's disease. However, being a systemic disease, PAS-positive macrophages and bacilli have been detected in almost all organs, including the CNS, eye, heart, lung, kidney, liver, spleen, lymph nodes and bone marrow. Involvement of heart valves has been noted in one-third of autopsy cases. A recent autopsy series found a wide spectrum of abnormalities in the coronary arteries of individuals with Whipple's disease (19).

The four most common manifestations are weight loss, diarrhea, migratory arthralgia and abdominal pain. Early gastrointestinal symptoms are nondescript, often diagnosed as inflammatory bowel disease. Weight loss and diarrhea are observed less frequently in patients who are diagnosed before the age of 40 years. Gastrointestinal symptoms may be preceded for months to years by nongastrointestinal symptoms, most commonly migratory, seronegative, nondeforming arthralgias. Arthritis, if it occurs, is most often an oligoarthritis involving the major limb and girdle joints. Extraintestinal disease most frequently involves the heart and CNS. Cases having neurological, cardiac or ocular involvement without overt gastrointestinal manifestations have been increasingly reported (20-27). Cases having CNS involvement without systemic involvement are characterized primarily by dementia, headaches, meningitis, myoclonus, seizures and somnolence. Probably all patients with Whipple's disease have CNS involvement, but it may not be clinically obvious. Unusual presentations may include abdominal pain, increased skin pigmentation, lymphadenopathy (including mediastinal widening), chronic nonproductive cough, pleural effusion, pleuritis and cardiac murmurs. All of the clinical eye manifestations are nonspecific, including glaucoma, chemosis, retinal hemorrhage, papilledema, fibrovascular pannus, corneal ulcers, optic atrophy and epiphora. From a diagnostic viewpoint, clinicians should include Whipple's disease in the differential diagnosis of patients with chronic bilateral retinitis and vitritis, especially if these disorders are associated with CNS manifestations (8).

Histopathological analysis of jejunal biopsy is the most commonly employed diagnostic procedure, looking for PASpositive, diastase-resistant inclusions on light microscopy. PCR is a significant advance in the diagnosis of Whipple's disease and has been increasingly applied for diagnostic purpos- 
es. Despite the historical 'rarity' of Whipple's disease, the increasing number of reports of the PCR detection of $T$ whippelii in tissue samples from patients without intestinal manifestations underscores the importance of considering Whipple's disease in patients with atypical presentations or undiagnosed infectious illnesses suggestive of an infectious etiology.

The prognosis of Whipple's disease is considered poor without treatment. Original treatment success with chloramphenicol was largely ignored, until an infectious etiology was confirmed by electron microscopy. Further studies (28) have removed doubts about the need for antimicrobials for treatment of the disorder. Although there are no randomized, placebo-controlled trials to provide guidance as to the optimal antimicrobial treatment, evidence from case series and retrospective analyses suggests that the organism is likely susceptible to many commonly used agents. The therapy most often cited with clinical success (5) is a course of parenteral penicillin and streptomycin or a thirdgeneration cephalosporin for two weeks, followed by a course of oral trimethoprim/sulphamethoxazole for one year. None of the 16 patients with CNS manifestations relapsed on trimethoprim/sulphamethoxazole (29). An alternate oral regimen is doxycycline or penicillin V. Despite effective antibiotics, CNS relapse may occur, often years after the original treatment. It is the major long term concern for which patients should be periodically assessed. Many unanswered questions remain with respect to risk factors for relapse and optimal management postrelapse. In addition, it is unknown whether routine PCR-based analysis of cerebrospinal fluid or intestinal biopsy specimens would be helpful in monitoring the progress both on and off therapy. As the spectrum of disease manifestations continues to expand, particularly in the absence of gastrointestinal symptoms, and with a new array of diagnostic tools, clinicians must be ever vigilant in considering the diagnosis of Whipple's disease in cases of culture-negative endocarditis, uveitis, unusual arthropathies and neurological disease, especially occurring post-treatment for Whipple's disease. It is also possible that subclinical or transient cases of Whipple's disease will be discovered in the years to come as our knowledge improves regarding the natural history of the disease, given the improvements in diagnostic capabilities.

\section{REFERENCES}

1. Swartz M. Whipple's disease - past, present and future. N Engl J Med 2000;342:648-50.

2. Relman DA, Schmidt TM, MacDermot RP, Falkow S. Identification of the uncultured bacillus of Whipple's disease. N Engl J Med 1992;327:293-301.

3. Wilson KH, Blitchington R, Frothingham R, Wilson JAP. Phylogeny of the Whipple's disease-associated bacterium. Lancet 1991:338:474-5.

4. Raoult D, Birg ML, La Scola B, et al. Cultivation of the bacillus of Whipple's disease. N Engl J Med 2000;342:620-5.

5. Maiwald M, Relman DA. Whipple's disease and Tropheryma whippelii: secrets slowly revealed. Clin Infect Dis 2001;32:457-63.

6. Maiwald M, Ditton HJ, von Herbay A, Rainey FA,
Stackebrandt E. Reassessment of the phylogenetic position of the bacterium associated with Whipple's disease and determination of the $16 \mathrm{~S}-23 \mathrm{~S}$ ribosomal intergenic spacer sequence. Int J Syst Bacteriol 1996;46:1078-82.

7. Schoeden G, Goldenberger D, Forrer R, et al. Deactivation of macrophages with interleukin-4 is the key to the isolation of Tropheryma whippelii. J Infect Dis 1997;176:672-7.

8. Dobbins WO. Whipple's Disease. Springfield: Charles C Thomas, 1987.

9. Maiwald M, Meier-Willerson HJ, Hartmann M, von Herbay A. Detection of Tropheryma whippelii DNA in a patient with AIDS. J Clin Microbiol 1995;33:1354-6.

10. Marth T, Roux M, von Herbay AM, et al. Persistent reduction of complement receptor 3 alpha-chain expressing mononuclear blood cells and transient inhibitory serum factors in Whipple's disease. Clin Immunopathol 1994;72:217-26.

11. Groll A, Valberg LS, Simon JB, et al. Immunopathology 1994;72:217-26.

12. Martin FF, Wilseck J, Dobbins WO III, et al. Immunological alterations in patients with treated Whipple's disease. Gastroenterology 1972;63:6-18.

13. Eck M, Keipe H, Harmsen D, et al. Invasion and destruction of mucosal plasma cells by Tropheryma whippelii. Hum Pathol 1997;28:1424-8.

14. Bjerkness R, Odegaard S, Bejerkvig R, et al. Whipple's disease: Demonstration of a persisting monocyte and macrophage dysfunction. Scand J Gastroenterol 1988:23:611-9.

15. Fredricks DM, Relman DA. Cultivation of Whipple bacillus: the irony and the ecstasy. Lancet 1997;350:1262-3.

16. Maiwald M, Schuhmacher F, Ditton HJ, von Herbay A. Environmental occurrence of the Whipple's disease bacterium. Appl Environ Microbiol 1998;64:760-2.

17. Street S, Donoghue HD, Neild GH. Tropheryma whippelii DNA in saliva of healthy people. Lancet 1999:354:1178-9.

18. Ehrbar HU, Bauerfeind P, Dutly F, Koelz HR, Altwegg M. PCR-positive tests for Tropheryma whippelii in patients without Whipple's disease. Lancet 1999:353:2214.

19. James TN. On the wide spectrum of abnormalities in the coronary arteries of Whipple's disease. Coron Artery Dis 2001;12:115-25.

20. Adams M, Rhyner PA, Day J, DeArmond S, Smuckler E. Whipple's disease confined to the central nervous system. Ann Neurol 1987:21:104-8.

21. Avila MP, Jalkh AE, Feldman E, Trempe CL, Schepens CL. Manifestations of Whipple's disease in the posterior segment of the eye. Arch Ophthalmol 1984;102:384-90.

22. Rickman LS, Freeman WR, Green WR, et al. Uveitis caused by Tropheryma whippelii (Whipple's bacillus) (brief report). N Engl J Med 1995;332:363-6.

23. Knox DL, Green WR, Troncoso JC, et al. Cerebral ocular Whipple's disease: A 62-year odyssey from death to diagnosis. Neurology 1995;45:617-25.

24. Schwartz MA, Selhorst JB, Ochs Al, et al. Oculomasticatory myorhythmia: a unique movement disorder occurring in Whipple's disease. Ann Neurol 1986;20:677-83.

25. O'Duffy JD, Griffing WL, Li CY, Abdelmalek MF, Persing DH. Whipple's arthritis. Direct detection of Tropheryma whippelii in synovial fluid and tissue. Arthritis Rheum 1999;42:812-7.

26. Gubler JGH , Kuster M, Dutly F, et al. Whipple endocarditis without overt gastrointestinal disease. Ann Intern Med 1999;131:112-6.

27. Geissdorfer W, Wittmann I, Seitz G, et al. A case of aortic valve disease associated with Tropheryma whippelii infection in the absence of other signs of Whipple's disease. Infection 2001;29:44-7.

28. Trier JS, Phelps PC, Eidelman S, Rubin CE. Whipple's disease: light and electron microscope correlation of jejunal mucosal histology with antibiotic treatment and clinical status. Gastroenterology 1965;48:684-707.

29. Durand DV, Lecomte C, Cathebras P, et al. Whipple disease: clinical review of 52 cases. Medicine 1997;76:170-84. 


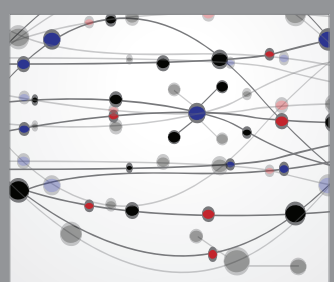

The Scientific World Journal
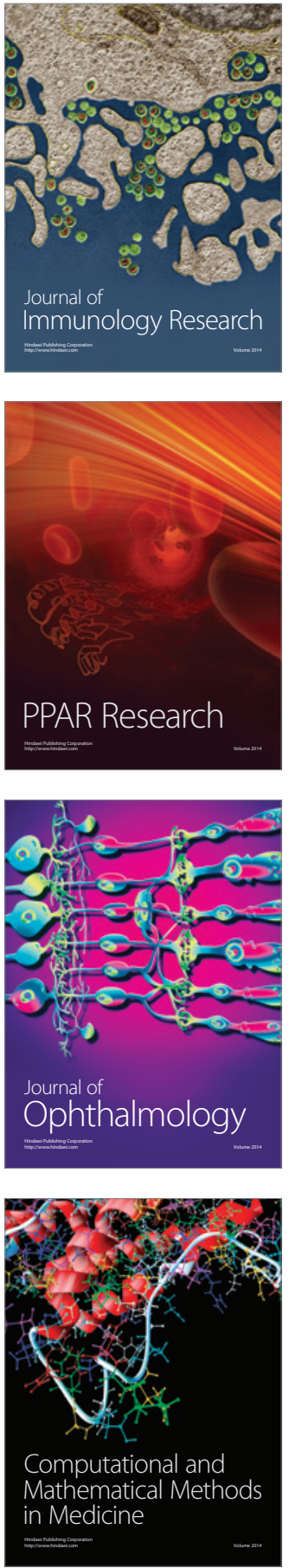

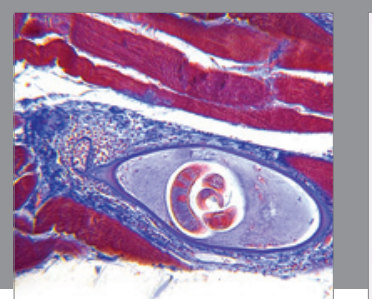

Gastroenterology Research and Practice

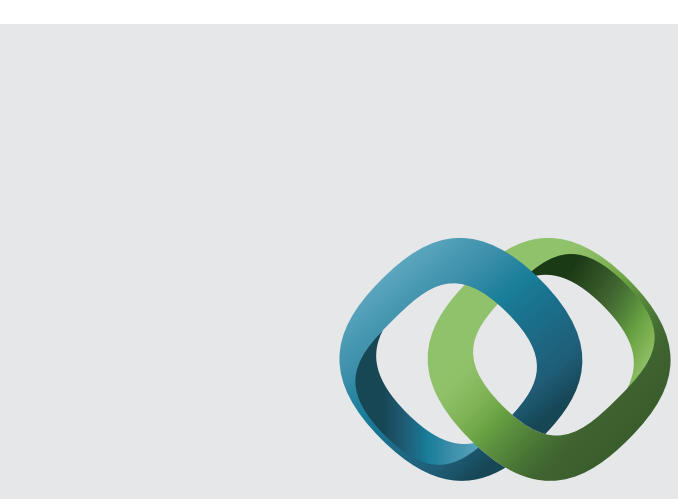

\section{Hindawi}

Submit your manuscripts at

http://www.hindawi.com
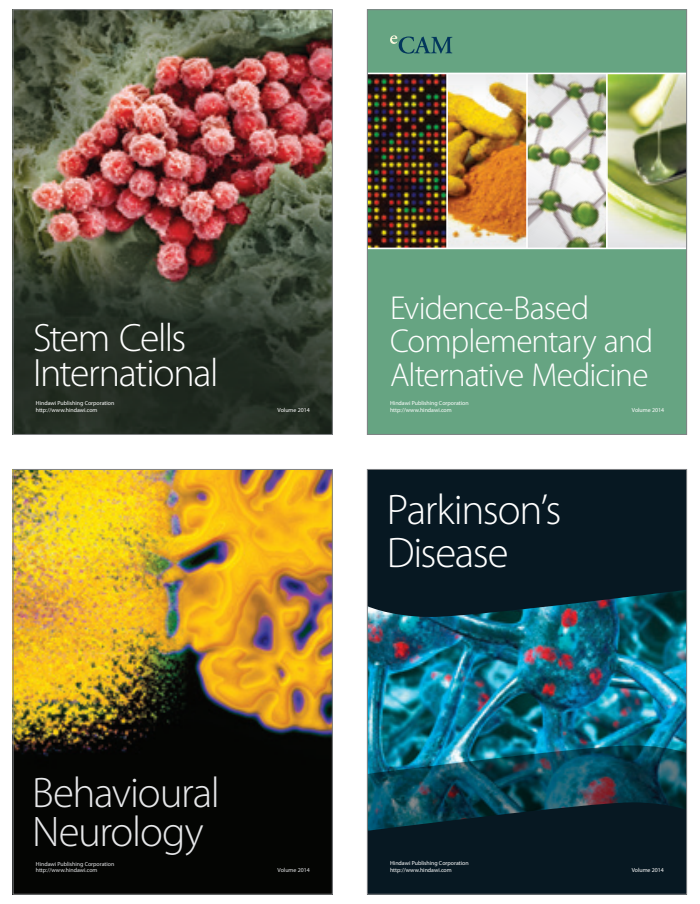
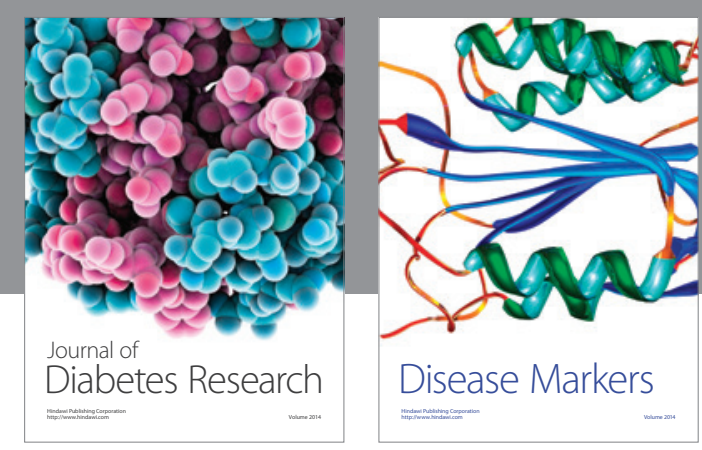

Disease Markers
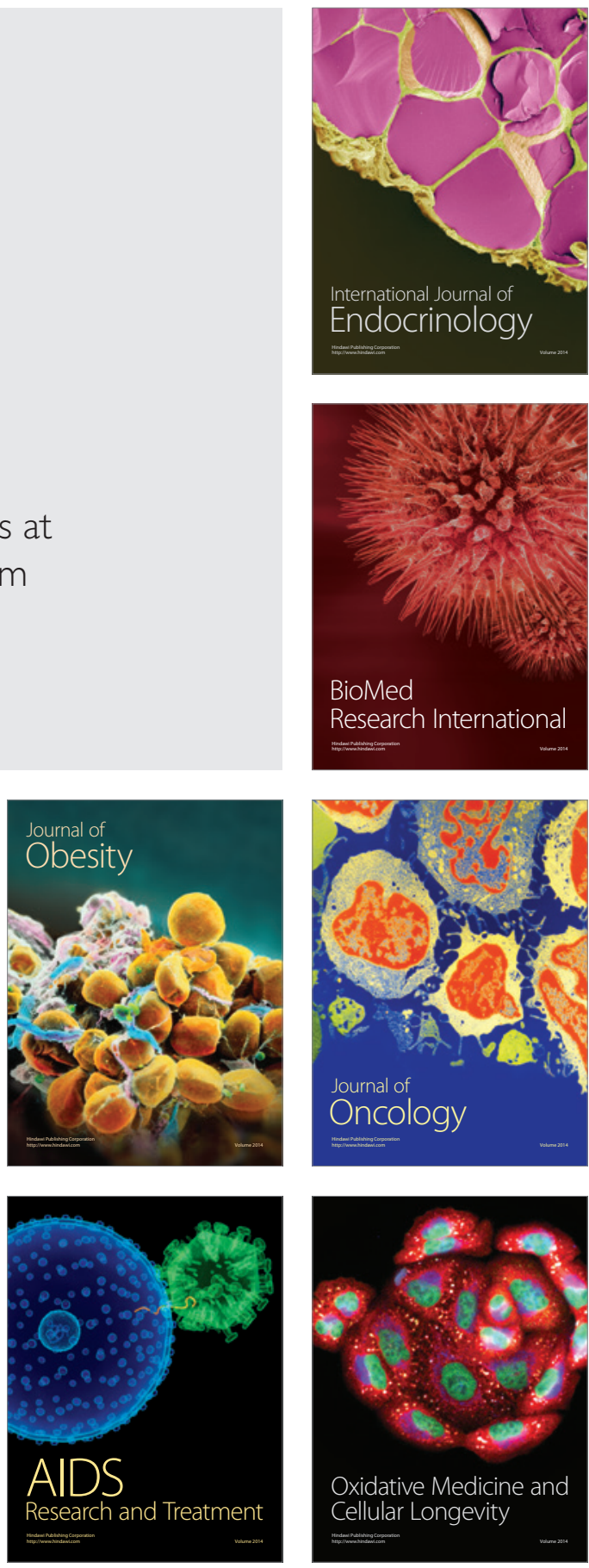